\title{
Sihler's stain visualization of myelinated cardiac plexus fiber attenuation in the AV node and the mitral valve as a result of heart failure
}

\author{
Alistair Hilton ${ }^{1}$, Adam Jorgensen ${ }^{1,2}$, Brett Gardiner ${ }^{1}$, Scott Robison ${ }^{1}$, H Wayne Lambert ${ }^{3}$, David A Morton ${ }^{4}$ and Jonathan J Wisco ${ }^{1,45 *}$ \\ ${ }^{1}$ Department of Physiology and Developmental Biology, Neuroscience Center, Brigham Young University, Provo, UT 84602, USA \\ ${ }^{2}$ Wake Forest School of Medicine, Winston-Salem, NC 27109, USA \\ ${ }^{3}$ Department of Pathology, Anatomy and Laboratory Medicine, West Virginia University School of Medicine, Morgantown, WV 26506, USA \\ ${ }^{4}$ Department of Neurobiology and Anatomy, University of Utah Medical School, Salt Lake City, UT 84132, USA \\ ${ }^{5}$ Department of Anatomy and Neurobiology, Boston University School of Medicine, Boston, MA 02118, USA
}

\begin{abstract}
A whole organ staining of myelinated cardiac plexus nerve fibers was conducted to visualize the cardiac innervation pathways in relation to heart failure. This visualization could better inform treatment for heart failure and contributory conditions, including arrhythmia, valve disease, and coronary artery disease. Two pathology-free human cadaveric heart specimens and one acute heart failure human cadaveric heart specimen were acquired as opportunity samples. One pathologyfree specimen was sectioned into three transverse slabs prior to staining, while the remaining pathology free specimen and the acute heart failure specimen were stained whole. Sihler's stain rendered the myocardium semi-translucent red-pink to purple, while the myelinated cardiac plexus fibers were stained a deep violet. Definitive nerve density was found in three major locations: along the coronary vessels, at the mitral valve, and in the ascending aorta, including the aortic valve. The Sihler's nonspecific staining of myelin indicates the presence of sympathetic and/or parasympathetic fibers. The pathology-free and diseased specimens were compared to determine what effect heart failure had on innervation patterns. Notable differences were found in the left anterior descending coronary artery, the atrioventricular $(\mathrm{AV})$ node, the left ventricle, the mitral valve, and the pulmonary trunk. The diseased heart showed attenuated nerve staining in both the AV node and mitral valve, supporting the relationship between parasympathetic withdrawal and heart failure.
\end{abstract}

\section{Introduction}

Heart failure represents a serious challenge to current medical care, currently affecting 5 million people in the United States [1], characterized by a reduced myocardial capacity to pump blood [2]. It is the single most common reason patients over 65 are admitted to the hospital [3], with involvement in one out of every nine deaths in 2009 [1], causing an estimated $\$ 32$ billion each year [4]. Arrhythmia is another serious heart condition characterized by irregular conduction or formation of neural impulses, leading to irregularity of atrial and ventricular beats [5]. Atrial arrhythmias have been estimated to affect 4 percent of elderly people, with ventricular arrhythmias affecting a third of the elderly [6]. The most serious effects of arrhythmia include sudden cardiac arrest and stroke, with $10 \%$ of stroke deaths at age 70 being connected with arrhythmia [6].

Heart failure and arrhythmias are tied to autonomic dysfunction; it is well understood that sympathetic hyper-innervation is a causative factor of heart failure $[7,8]$. Similarly, in arrhythmias sympathetic hyperinnervation occurs following myocardial infarction, leading to adverse outcomes $[9,10]$. However, the role of parasympathetic innervation in these diseases remains less clear. Recent studies have begun to examine the specific role of the parasympathetic nervous system in heart failure but are still in earlier stages of understanding $[10,11]$.

The heart is innervated by the autonomic nervous system, which consists of the two aforementioned divisions: the sympathetic and parasympathetic nervous systems. The efferent fibers of the sympathetic nervous system originate from the spinal cord, with shorter preganglionic neurons, and longer postganglionic neurons. Those postganglionic fibers that innervate the heart originate primarily from the stellate (cervicothoracic) ganglia [12]. The efferent parasympathetic fibers consist of short postganglionic fibers from the cardiac ganglia, which receive preganglionic signals from the vagus nerve [10]. In both sympathetic and parasympathetic systems, the preganglionic neurons are myelinated, while the postganglionic neurons are not [13]. Sensory fibers of the heart consist of both divisions. They are myelinated and unmyelinated afferent fibers arising throughout the chambers of the heart and travel with the sympathetic fibers to the spinal cord. [14]. Additionally, thick myelinated and thin unmyelinated afferent vagal fibers (C fibers) arise from atrial myocardium [13]. Though the ventricles have previously shown attenuated parasympathetic

${ }^{\star}$ Correspondence to: Jonathan J Wisco, Associate Professor, Boston University School of Medicine, Department of Anatomy and Neurobiology, Laboratory for Translational Anatomy of Degenerative Diseases and Developmental Disorders (TAD4), 72 E Concord St, L-1004, Boston, MA 02118, Tel: 617-358-2002, 310 746-6647; E-Mail: jjwisco@bu.edu

Key words: Sympathetic hyper-innervation, parasympathetic withdrawal, aortic valve nerve fibers, coronary vessel nerve fibers, bicuspid valve nerve fibers

Received: June 27, 2018; Accepted: August 28, 2018; Published: September 04 2018 
innervation compared to sympathetic, recent study has also found significant parasympathetic innervation of the endocardium and epicardium of the ventricles [15].

In order to visualize the complex cardiac plexus, a whole mount nerve staining technique called Sihler's Stain was used. The stain selectively targets the axons of the neurons, since the hematoxylin interacts with only the myelin surrounding them [16-18]. As such, the stain allows for visualization of myelinated nerve fibers only. This means the staining will consist primarily of the vagal fibers, both preganglionic efferents and the thick myelinated afferents, with some of the staining potentially being from the myelinated afferent sympathetic fibers.

The Sihler's staining technique has a long history. It was first utilized in the late $19^{\text {th }}$ century by Dr. Charles Sihler to demonstrate the distribution of fine nerve endings [19]. Over the next half century, it was used sporadically to investigate innervation of various tissues: first by Wharton to study the human urinary tract and female monkey reproductive organs [20], then by Williams for the lower limbs of a human fetus [21], and by Freihofer in fish [22]. The Sihler's stain technique was modified in the late $20^{\text {th }}$ century by two teams: Liem and Douwe van Willigen [16] and Sanders and $\mathrm{Wu}$ [23], the latter of which used it to study both canine and human larynxes [24,25]. This modified protocol has since been used with increasing frequency to study the innervation of various organ and muscle tissue, particularly for fine nerve endings. Recently, the technique has been reviewed separately by both $\mathrm{Mu}$ and Sanders [17] and Won [18] and shown to be particularly effective in revealing intramuscular innervation pathways.

\section{Methods}

Two pathology-free human cadaveric heart specimens and one acute heart failure human cadaveric heart specimen were acquired through the West Virginia University School of Medicine (WVUSOM) Human Gift Registry. One pathology-free heart was then cut transversely into three sections. Sihler's stain technique was performed on each section individually to visualize cardiac plexus nerve fibers. The remaining pathology-free heart and the acute failure heart were left whole and treated with the same staining technique as the transverse sections, with slightly lengthened time spans accounting for the difference in specimen size.

The modified Sihler's Stain uses six different solutions in a sequence of steps. This technique $[17,18]$ was followed with minor alterations to two of the solutions. Since chloral hydrate is a controlled substance in the United States, Sihler's solution I and Sihler's solution II (numbers 3 and 4) were both modified to replace chloral hydrate with the commercially available Visikol, which has been shown to be an effective substitute [26]. The resulting solutions are as follows:

\section{1. $10 \%$ un-neutralized formalin.}

2. $3 \%$ aqueous potassium hydroxide $(\mathrm{KOH})$ solution (add three drops of $3 \% \mathrm{v} / \mathrm{v}$ hydrogen peroxide to $100 \mathrm{ml} 3 \% \mathrm{w} / \mathrm{v} \mathrm{KOH}$ solution for depigmentation).

3. Sihler's Solution I (17 volumes glacial acetic acid, 17 volumes glycerin and one volume Visikol).

4. Sihler's Solution II (17 volumes Ehrlichs hematoxylin, 17 volumes glycerin and one volume Visikol).

5. Lithium carbonate solution $0.05 \% \mathrm{w} / \mathrm{v}$.

6. Aqueous glycerin $40 \%, 60 \%, 80 \% \mathrm{v} / \mathrm{v}$, and $100 \%$ glycerin.
The length of time left in each solution varies with size of the specimen, and all times are approximations for the cardiac tissue, as designated.

\section{Fixing}

First the tissue is washed in running tap water before being placed in $10 \%$ un-neutralized formalin. The cardiac tissue was left in this solution for 3-4 weeks.

\section{Depigmentation}

The fixed tissue is then washed in running water for approximately one hour. It is then placed in 3\% aqueous potassium hydroxide for depigmentation. This process is again dependent on the size and thickness of the tissue being studied, with cardiac tissue taking 3-4 months. This solution should be changed 2-3 times a week, or whenever the solution becomes a cloudy amber color. This step will incrementally whiten the tissue, the end point being when it is a whitegray translucent hue.

\section{Decalcification}

This depigmented specimen is again washed under running water for one hour and placed in Sihler's solution I for decalcification for 2-4 weeks. This solution needs changing once weekly.

\section{Staining}

After washing under running water for 30 minutes, the tissue is placed in Sihler's solution II to stain the nerve fibers. The cardiac tissue remained in solution for 4-6 weeks. This solution may be changed periodically if the color goes from dark red-violet to a lighter purple. The stain did not need changing for the cardiac tissue. This step is completed when the entirety of the tissue is stained a deep red-violet.

\section{Destaining}

The stained tissue is again washed under running water for 30 minutes and placed in Sihler's solution I again and gently shaken for destaining. The cardiac tissue was placed in solution for 4-6 hours with agitation. After each hour, the bath is replaced with a fresh solution. After 6 hours, the specimen was bathed overnight. This was sufficient for the transverse sections, but the whole hearts required an additional 6-8 hours of destaining with agitation. The solution should be changed when it becomes a dark orange or yellow and checked frequently to determine when to stop destaining. This step is completed when the nerve fibers can be clearly seen as a violet, while the surrounding tissue is a red-pink hue. During destaining of the whole hearts, different tissues were shown to destain at different rates, with the greater vessels, coronary vessels, and valves destaining at a more rapid rate than the myocardium. Since theses tissues destained more rapidly, in order to preserve the definite nerve stain found there the destaining process was stopped when these locations began to show signs of lightening.

\section{Neutralization}

The tissue is slightly acidic following destaining, and needs to be neutralized. After washing under running tap water for one hour, the specimen is placed in $0.05 \%$ lithium carbonate solution and gently shaken. This solution should be changed whenever it turns orange or yellow. The cardiac tissue was in this solution for 1-2 hours. This is complete when the nerve fibers are a deeper purple while the surrounding tissue is a light red-pink hue. 


\section{Clearing}

The next step is to wash the tissue again under running tap water for one hour and placed in increasing concentrations $(40,60,80 \%)$ of aqueous glycerin solution to clear the tissue of excess stain. The tissue is left in each solution for 2-4 days, and the solution should be changed when it turns an amber color. This step is completed when the nerve fibers in the specimen can be clearly seen and the surrounding tissue is destained.

\section{Transparency}

The tissue can now be stored in $100 \%$ glycerin for transparency.

\section{Results}

The Sihler's stain technique revealed nerve density throughout the heart. A full description of the nerve staining found in the transverse sections and whole hearts is presented in Table 1, with Heart A being the transverse sections, Heart B the healthy whole heart, and Heart $\mathrm{C}$ the whole heart with heart failure. A summary is presented below.

In Heart A, definitive nerve density was observed in three major locations: along the coronary arteries, at the mitral valve, and at the aortic valve (Figure 1a). Outside of these locations, there was little nerve staining found. Nervous tissue was found along the tracks of two of the coronary arteries: the left anterior descending and posterior descending arteries (Figure $1 \mathrm{~b}$ and $\mathrm{d}$ ). The mitral valve had nerve density on both the anterior and posterior leaflet, with a greater concentration in the anterior leaflet (Figure 1b). The concentration was greatest in the proximal regions of the valve, extending slightly distally towards the attachments of the chordae tendineae (Figure 1c). There also appears to be light nerve stain present in the papillary muscles and

Table 1. Summary description of Sihler's Stain results between non-heart failure (section and whole) and heart failure hearts

\begin{tabular}{|c|c|c|c|}
\hline & Heart A- Transverse Sections & Heart B- Whole Heart & Heart C- Whole Heart \\
\hline Demographic Information & 81-year-old Female & 66-year-old Female & 77-year-old Female \\
\hline Cause of Death & $\begin{array}{l}\text { Multiple organ failure, respiratory failure, } \\
\text { interstitial pneumonia }\end{array}$ & Small cell lung cancer & Acute heart failure, coronary artery disease \\
\hline \multicolumn{4}{|l|}{ Coronary Arteries } \\
\hline Right Coronary & N/A & $\begin{array}{l}\text { Thin purple line along a single terminal branch exiting the } \\
\text { adipose tissue }\end{array}$ & $\begin{array}{l}\text { Light purple tracing multiple terminal ends of vessel } \\
\text { within adipose tissue }\end{array}$ \\
\hline Posterior Descending & $\begin{array}{l}\text { Nerve staining along length of vessel } \\
\text { embedded in adipose tissue, darkest around } \\
\text { rims of vessel where cut }\end{array}$ & Light potential nerve stain & $\begin{array}{l}\text { Faint purple cutting transversely across posterior } \\
\text { side, between right atrium and ventricle, staining } \\
\text { gets much lighter continuing posteriorly }\end{array}$ \\
\hline Left anterior descending & $\begin{array}{l}\text { Nerve staining along winding section of } \\
\text { vessel attached to left ventricle exterior wall }\end{array}$ & Slight shimmery purple stain, potentially nerve fibers. & $\begin{array}{l}\text { Noticeable purple nerve stain along two branchings } \\
\text { of the vessel. Definitive patch of nerve stain on } \\
\text { medial branch } 3-4 \mathrm{~cm} \text { from origin }\end{array}$ \\
\hline Circumflex & N/A & Possible stain. & Faint staining along more proximal portions \\
\hline \multicolumn{4}{|l|}{ Chambers } \\
\hline \multicolumn{4}{|l|}{ Right Atrium } \\
\hline Exterior & N/A & Light purple throughout posterior side & $\begin{array}{l}\text { Light purple coloration on small patch beside the } \\
\text { aorta }\end{array}$ \\
\hline Interior & N/A & $\begin{array}{l}\text { Darker purple color on the posterior inferior region, } \\
\text { posterior to the tricuspid valve, along floor of the chamber. } \\
\text { Potential nerve staining (roughly } 0.5 \mathrm{~cm} \text { square) located } \\
\text { about } 0.5 \mathrm{~cm} \text { posterior to septal cusp about } 1 \mathrm{~cm} \text { off midpoint } \\
\text { of valve }\end{array}$ & $\begin{array}{l}\text { Moderate purple color on superior and medial } \\
\text { portion of the chamber wall, running up towards the } \\
\text { superior vena cava. Small nerve stain dot roughly } \\
1 \mathrm{~cm} \text { posterior to septal cusp, about } 1 \mathrm{~cm} \text { off midpoint } \\
\text { of valve }\end{array}$ \\
\hline \multicolumn{4}{|l|}{ Right Ventricle } \\
\hline Exterior & N/A & $\begin{array}{l}\text { Moderate uniform purple on anterior face, shading to } \\
\text { darker, deep purple along the right/posterior side }\end{array}$ & $\begin{array}{l}\text { Faint purple coloration on anterior region, little to no } \\
\text { staining on posterior surface }\end{array}$ \\
\hline Interior & N/A & $\begin{array}{l}\text { Light purple tint on trabeculae carneae, slightly more on } \\
\text { posterior side, more in inferior half of chamber }\end{array}$ & $\begin{array}{l}\text { Moderate purple hue within the trabeculae carneae } \\
\text { along the more superior regions of the chamber, } \\
\text { rimming the wall inferior to the tricuspid valve, and } \\
\text { beneath the pulmonary valve. Slightly more on the } \\
\text { anterior wall and interventricular septum. Staining } \\
\text { within papillary muscles }\end{array}$ \\
\hline \multicolumn{4}{|l|}{ Left Atrium } \\
\hline Exterior & N/A & $\begin{array}{l}\text { Red purple along inferior border with the left ventricle/ } \\
\text { coronary sinus }\end{array}$ & $\begin{array}{l}\text { No noticeable staining. Strange patches of hard/ } \\
\text { rough black tissue }\end{array}$ \\
\hline Interior & N/A & $\begin{array}{l}\text { Light purple along superior region where the pulmonary } \\
\text { veins join the atrium. Moderate red purple along chamber } \\
\text { floor, particularly posterior to mitral valve }\end{array}$ & $\begin{array}{l}\text { Light purple on superior region near insertion of } \\
\text { pulmonary veins }\end{array}$ \\
\hline \multicolumn{4}{|l|}{ Left Ventricle } \\
\hline Exterior & N/A & $\begin{array}{l}\text { Dark red purple throughout, darker on the posterior side } \\
\text { compared to anterior. Darkest region is along the left side, } \\
\text { slightly posterior }\end{array}$ & $\begin{array}{l}\text { Dark purple throughout, darker on anterior versus } \\
\text { posterior side. Darkest region along the left border, } \\
\text { from anterior to posterior color change starts dark, } \\
\text { darkens on the side, then steadily lightens along the } \\
\text { posterior side. Slightly darker inferiorly, towards } \\
\text { apex }\end{array}$ \\
\hline Interior & N/A & $\begin{array}{l}\text { Light purple on papillary muscles, moderate purple on } \\
\text { superior left side wall of the trabeculae carneae, just inferior } \\
\text { to mitral valve }\end{array}$ & $\begin{array}{l}\text { Purple stain throughout the wall, concentrated darker } \\
\text { to inferior region, towards apex. Shining purple stain } \\
\text { on anterior wall underneath valves in gap between } \\
\text { leaflets. Purple nerve stains within papillary muscles }\end{array}$ \\
\hline
\end{tabular}




\begin{tabular}{|c|c|c|c|}
\hline \multicolumn{4}{|l|}{ Valves } \\
\hline Tricuspid & N/A & No noticeable staining & No noticeable staining \\
\hline Mitral & $\begin{array}{l}\text { Definitive nerve stain, partircularly } \\
\text { noticeable from the inferior aspect, with } \\
\text { nerve stain along more proximal rim of the } \\
\text { valve. Thick band of nerve stain about } 1 \mathrm{~cm} \\
\text { wide running along edge of anterior leaflet } \\
\text { with bundles branching down to chordae } \\
\text { tendineae }\end{array}$ & $\begin{array}{l}\text { Definite nerve staining within valve, anterior leaflet, along } \\
\text { more proximal region, visible from superior and inferior } \\
\text { sides. From superior view, lighter on left side, darkest just } \\
\text { left of middle }(1 \mathrm{~cm} \text { square) connected by thin band to dark } \\
\text { patch on right edge (1cm square) }\end{array}$ & $\begin{array}{l}\text { No noticeable staining from superior aspect. } \\
\text { Moderate nerve staining of anterior leaflet visible } \\
\text { from inferior view, along proximal ridge. Nerve } \\
\text { staining along chordae tendineae }\end{array}$ \\
\hline Pulmonary & N/A & No noticeable staining & No noticeable staining \\
\hline Aortic & $\begin{array}{l}\text { Nerve staining along remaining rim of aorta } \\
\text { wall, with significant nerve stain in the } \\
\text { inferior portions of the remaining cusp }\end{array}$ & $\begin{array}{l}\text { Significant nerve staining rimming the superior border of } \\
\text { each cusp on aorta wall }\end{array}$ & $\begin{array}{l}\text { Nerve staining along the rims of the aorta above } \\
\text { the valve. Nerve staining within the distal portions } \\
\text { of the valve, particularly the central portion of the } \\
\text { right cusp }\end{array}$ \\
\hline \multicolumn{4}{|l|}{ Vessels } \\
\hline \multicolumn{4}{|c|}{ Pulmonary Trunk } \\
\hline Exterior & N/A & No noticeable staining & $\begin{array}{l}\text { Definite nerve staining around the inferior part of the } \\
\text { rim of the proximal portion right pulmonary artery, } \\
\text { (1 } \mathrm{cm} \text { square) }\end{array}$ \\
\hline Interior & N/A & $\begin{array}{l}\text { Extremely faint purple hue superior to the corners of the } \\
\text { pulmonary valve }\end{array}$ & No noticeable staining \\
\hline \multicolumn{4}{|c|}{ 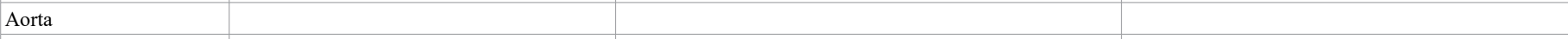 } \\
\hline Exterior & N/A & $\begin{array}{l}\text { Anterior side has light purple staining, with a few sections } \\
\text { of darker bands. Posterior side, superior to LA and medial } \\
\text { from pulmonary trunk, patch of definitive purple staining, } \\
(2 \mathrm{~cm} \text { by } 4 \mathrm{~cm})\end{array}$ & Light purple coloration throughout exterior \\
\hline Interior & N/A & $\begin{array}{l}\text { Dark staining rimming superior border of each cusp along } \\
\text { aorta wall. Dark stain extends up surrounding the origins } \\
\text { of the coronary arteries. Larger area covered superior to } \\
\text { left cusp, patches continue roughly } 4 \mathrm{~cm} \text { above LCA origin. } \\
10 \mathrm{~cm} \text { above valve level dark purple nerve staining along } \\
\text { rim of where vessel was cut }\end{array}$ & $\begin{array}{l}\text { Obvious nerve staining throughout, patches } \\
\text { concentrated along the left wall, running up from the } \\
\text { left cusp, with two particularly dark patches } 10-15 \mathrm{~cm} \\
\text { above valve level. Dark nerve staining above the } \\
\text { corners of the cusps. Dark nerve staining on origins } \\
\text { of coronary arteries, particularly LCA }\end{array}$ \\
\hline
\end{tabular}

chordae tendineae. Although only one cusp of the aortic semilunar valve remained intact throughout the sectioning and staining process, on this cusp the nerve density was on the superior side of the valve, with it being most concentrated in the more basal regions (Figure 1b).

In Hearts B and C, limited nerve stain was found within the interior of the heart chambers, with the darkest stain overall being found in the exterior of the left ventricle (Figure 2). The right ventricle had possible staining on the exterior, with more noticeable staining along patches of the interior trabeculae carneae (Figure $2 \mathrm{~d}$ and i). The exterior of the left ventricle showed significantly darker staining than the right, with fairly clear nerve staining in the interior walls, rimming underneath the mitral valve (Figure 2a and $\mathrm{f}$, e and $\mathrm{j}$ ). Both Heart B and C showed little staining on the exterior of the left and right atria. The interior of the atria had light nerve staining. However, they showed a distinct patch of nerve staining in the posterior and inferior wall of the right atrium, located just posterior to the septal cusp of the tricuspid valve, corresponding to the atrioventricular (AV) node (Figure $3 \mathrm{c}$ and $\mathrm{d}$ ). The most obvious nerve staining was found in the same three locations as the transverse sections. Both showed some level of staining along the coronary arteries, with the left anterior descending artery being the greatest (Figure $3 \mathrm{a}$ and $\mathrm{b}$ ). The anterior leaflet of the mitral valve also contained nerve staining along the proximal portion in the two hearts (Figure $4 \mathrm{c}$ and $\mathrm{d}$ ). They also showed nerve staining around the aortic valve, within the rims of the cusps themselves, as well as the wall of the aorta rimming the upper side of the cusps (Figure 4e and f). The two full hearts also had dark and obvious nerve staining on the inner walls of the ascending aorta (Figure $4 \mathrm{a}$ and $\mathrm{b}$ ).

Differences in nerve staining between Heart B and C were found in multiple locations: the left anterior descending artery, the AV node, the interior and exterior of the left ventricle, the mitral valve, and the

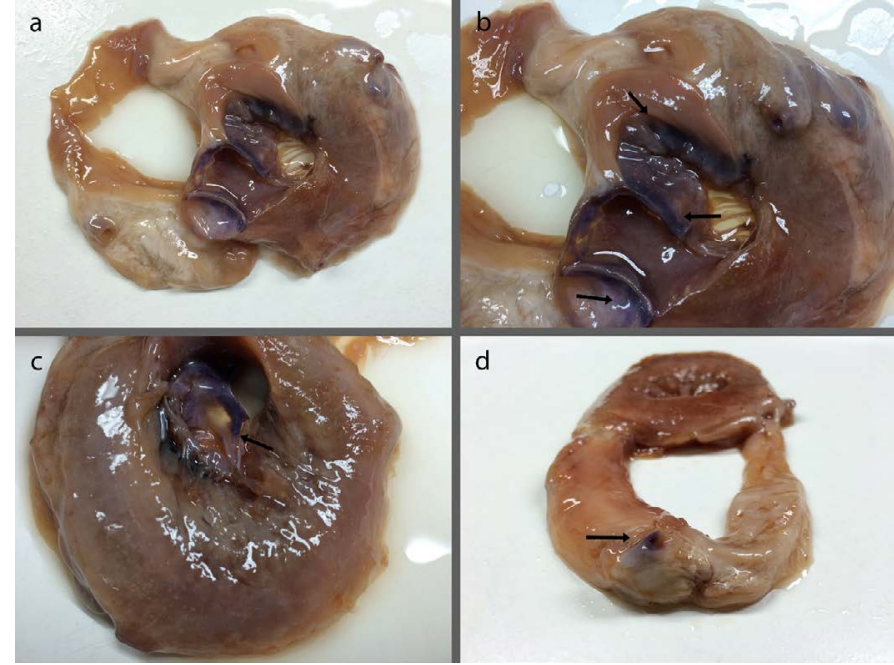

Figure 1. (a) Superior view of Heart A slab demonstrating nerve staining within the mitral valve, the surviving cusp of the aortic valve, and a coronary artery; (b) Magnified superior view of Heart A slab highlighting darker nerve stain in the mitral valves distal regions and within the cusp of the aortic valve (arrows); (c) Inferior view of the Heart A slab showing the anterior leaflet of the mitral valve (arrow) with clear nerve stain in the distal regions tapering off down towards the chordae tendineae; (d) Superior view of second Heart A slab showing dark nerve staining along the rim of the exposed coronary artery (arrow).

pulmonary arteries (Figure 3). Two additional exceptions were found between the two whole hearts. In the Heart B, a patch of nerve stained tissue was found on the more posterior side, underneath the arch of the aorta, between the arch and the superior portion of the pulmonary trunk (Figure 3e). This location most likely corresponds to the deep cardiac plexus, but could be part of the superficial cardiac plexus, or 


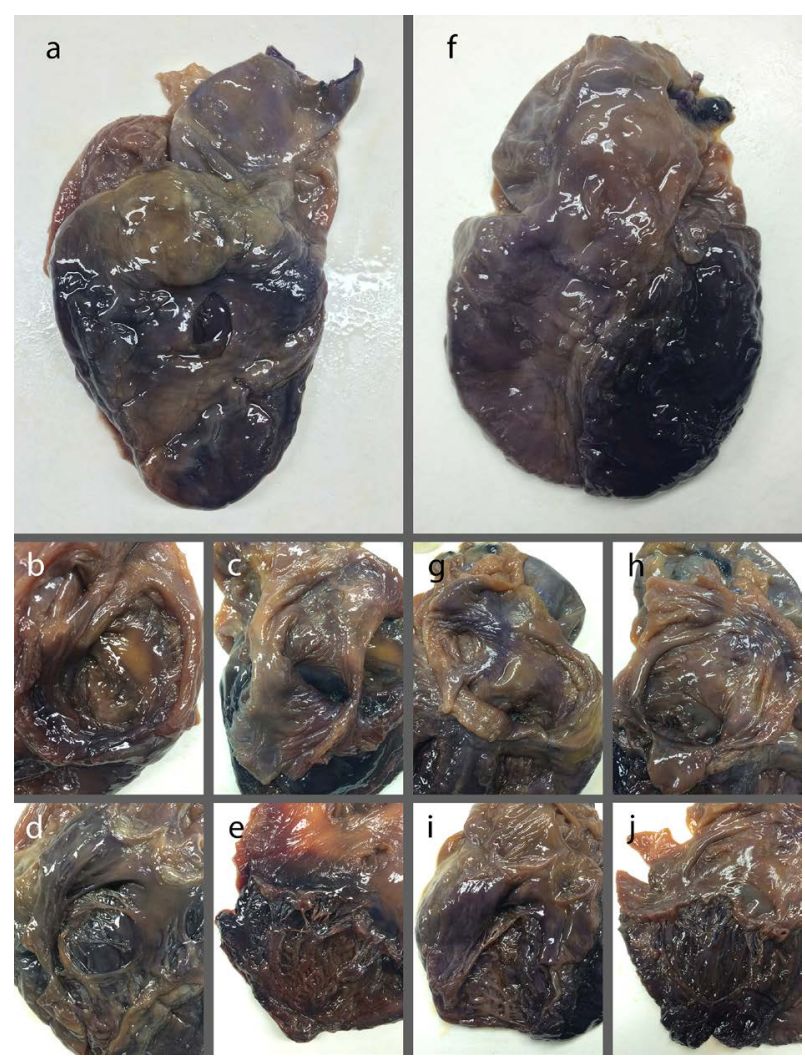

Figure 2. (a) Anterior view of Heart B; (b) Posterior view of Heart B right atrium; (c) Posterior view of Heart B left atrium; (d) Anterior view of Heart B right ventricle; (e) Posterior view of Heart B left ventricle; (f) Anterior view of Heart C; (g) Posterior view of Heart $\mathrm{C}$ right atrium; (h) Posterior view of Heart $\mathrm{C}$ left atrium; (i) Anterior view of Heart $\mathrm{C}$ right ventricle; (j) Posterior view of Heart $\mathrm{C}$ left ventricle.

other ganglia of the cardiac plexus such as the ganglion of Wrisberg [13]. In Heart C, several black, rough patches of tissue were found within the fatty tissue on the posterior side of the heart, between the left atrium and the pulmonary trunk (Figure $3 \mathrm{f}$ ).

\section{Discussion}

The Sihler's Stain was proved effective at staining nervous tissue in the cardiac specimens. As previously mentioned, the hematoxlyin used in the staining protocol only reacts with the myelin of the nerve fibers and is therefore non-specific [16-18]. However, the majority of the myelinated fibers are more likely to be parasympathetic, given all efferent preganglionic and many afferent parasympathetic fibers are myelinated, whereas only some of the sympathetic afferents are. The finding of nerve supply along the coronary vessels is consistent with the current understanding of cardiac innervation [13]. The nerve density found on the valve structures, however, is more interesting. These findings agree with previous studies [27,28], and solidify a growing understanding that valves are not the strictly passive structures they've been previously understood to be. This finding has wide reaching potential impacts on cardiac valve disease, which constitutes an important part of global disease load [29]. One recent study into the nerve functions found the parasympathetic innervation of the mitral valve led to decreased valve stiffness [30]. Studies have been conducted looking for new approaches to valve disease [31], but more study to fully determine the visualized nerve fibers' functions is required to provide increased insight into these new approaches.

The lack of clear cardiac nerve plexus fibers found intramuscularly within the myocardium of the transverse slabs agrees with current understanding of the heart's electrical conducting myocyte pathway. The network of nerve staining within the walls of the ventricles and atria provides additional evidence for a greater abundance of parasympathetic fibers in the chambers than previously thought [15]. The darker staining on the exterior of the left ventricle compared to the right ventricle has interesting implications (Figure $2 \mathrm{a}$ and $\mathrm{f}$ ). This observation could indicate that the left side of the heart has a greater overall density of nerves within or around the epicardium, or it could be specific to the parasympathetic division.

However, this darker staining of the mycardium is not necessarily conclusive for nerve staining. As discussed previously, in the destaining step of the whole hearts, the greater vessels, coronary vessels, and valves destained more swiftly than the myocardium. Thus, the stain was stopped when the obvious nerve stains were beginning to be erased, which could explain the seemingly dark coloring of the myocardial tissue as simply a by-product of not fully destaining. This result would also explain the differential coloring between the right and left sides. The myocardial tissue is much thicker in the left ventricle compared to the right ventricle, and would logically take longer to de-stain fully. That being said, the myocardial tissue did not show a significant change

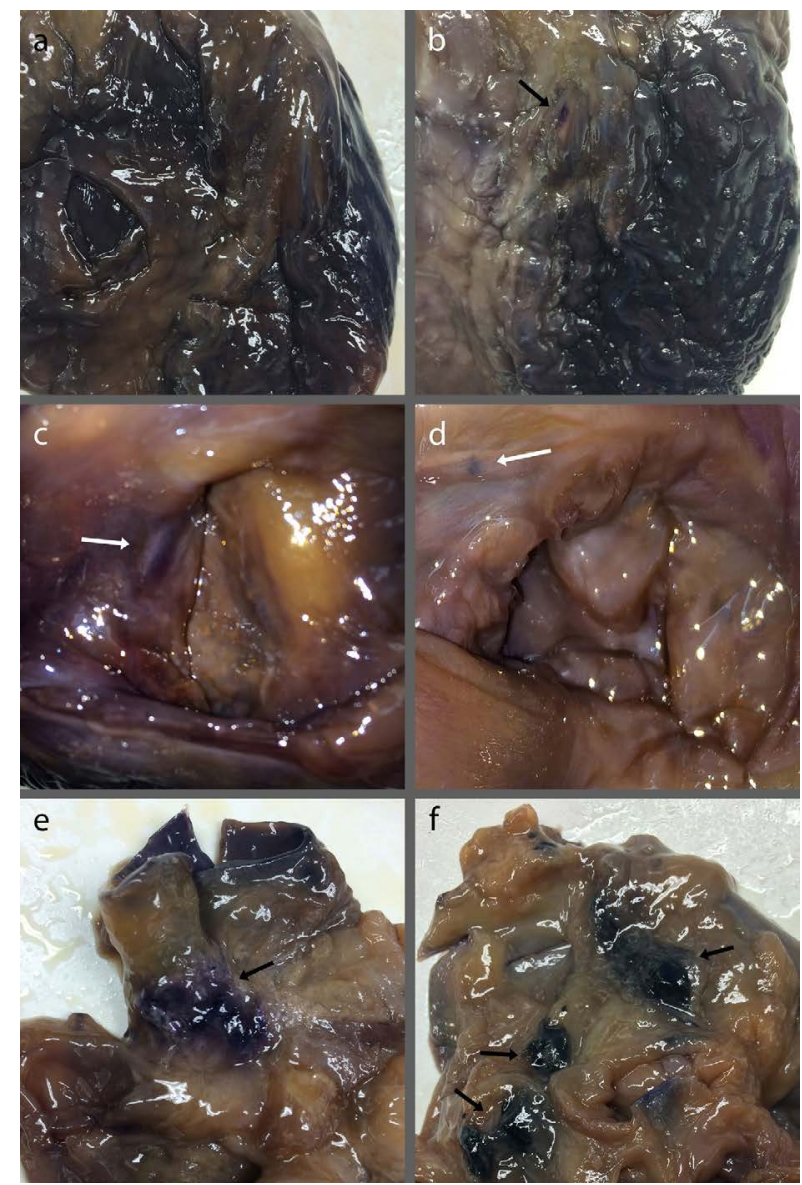

Figure 3. (a) Anterior view of Heart B denoting light staining along the left anterior descending artery; (b) Anterior view of Heart $\mathrm{C}$ with a distinct patch of nerve staining on the proximal portion of the left anterior descending artery (arrow) in addition to light staining throughout the vessels; (c) Superior view of Heart B right atrium with sizeable nerve staining of the AV node center left (arrow); (d) Superior view of Heart $\mathrm{C}$ right atrium with small, discrete nerve staining of the AV node upper left (arrow); (e) Posterior view of Heart B greater vessels with nerve staining correlating to cardiac plexus ganglia (arrow); (f) Posterior view of Heart $\mathrm{C}$ greater vessels showing rough, black patches of unknown tissue in addition to nerve staining along the rim of the right pulmonary artery in the lower right (arrows). 


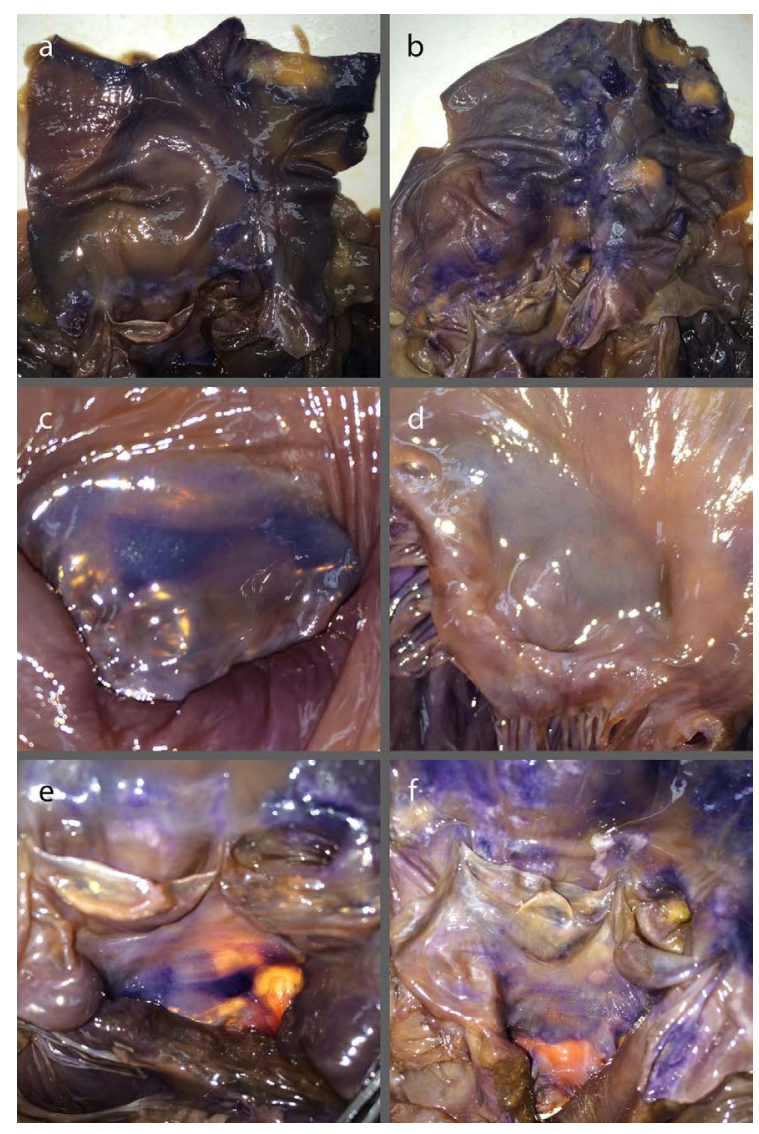

Figure 4. (a) Anterior view of Heart B interior of the aorta; (b) Anterior view of Heart $C$ interior of the aorta; (c) Superior view of Heart B mitral valve anterior leaflet; (d) Superior view of Heart $\mathrm{C}$ mitral valve anterior leaflet; (e) Anterior view of Heart B aortic valve cusps with inferior view of anterior leaflet of the mitral valve; (f) Anterior view of Heart $\mathrm{C}$ aortic valve cusps with inferior view of anterior leaflet of the mitral valve.

in the amount of staining during the last 3-4 hours of the destaining step, suggesting the stain could be a true positive for myelinated nerve fibers. Greater research is needed to confirm whether the darker staining of the ventricle exterior corresponds to nerve fibers.

The differences in the nerve staining between the healthy and diseased whole hearts merits further discussion. Though both hearts showed light staining along the coronary vessels, with the left anterior descending artery being the most obvious, Heart $\mathrm{C}$ had slightly darker nerve stain, with a discrete patch located $3-4 \mathrm{~cm}$ distally from the arteries origin (Figure 3a and b), which makes sense given Heart $\mathrm{C}$ suffered from coronary artery disease concurrent with heart failure. Coronary artery disease results in the narrowing of the arteries due to plaque accumulation, and vagal nerve activity has been shown to maintain the tonic dilation of coronary arteries [32]. It is therefore possible the greater staining is due to greater vagal innervation to attempt to keep the arteries from occluding.

The AV node was more obviously stained in Heart B than Heart C. Heart B showed a patch of nerve stain $1 \mathrm{~cm}$ by $0.5 \mathrm{~cm}$, while Heart $C$ had only a small dot of nerve stain in that location (Figure $3 \mathrm{c}$ and $\mathrm{d}$ ). The lack of stained myelinated fibers in Heart $\mathrm{C}$ suggests less innervation overall, and certainly less parasympathetic innervation. This observation fits with the current understanding that parasympathetic attenuation, along with sympathetic hyper-innervation, contribute to heart failure [8].
The differences found in the left ventricle are more puzzling. The nerve staining on both the exterior and interior of this chamber are darker in Heart $\mathrm{C}$ compared to Heart $\mathrm{B}$. The exterior staining difference is slighter, with both having the darkest portions of staining along the left margin of the chamber (Figure 2a and $\mathrm{f}$ ). In the interior, the difference is more distinct. Heart $\mathrm{B}$ shows little nerve staining along the walls overall, while Heart $\mathrm{C}$ has fairly apparent nerve staining along the interior walls of the vessel. Heart $C$ also shows distinct nerve staining within many of the chordae tendineae and distal portions of the associated papillary muscles (Figure $2 e$ and $j$ ). If the staining corresponds to parasympathetic fibers, this finding is a direct contradiction with the understanding of parasympathetic attenuation being associated with heart failure [8]. However, if these differences in the interior were instead due to sympathetic afferents, it would fit with the observed increase in sympathetic innervation with heart failure $[2,7,8]$. Recent studies have also shown greater parasympathetic fibers within the ventricles than previously thought [15] meaning more specificity of nerve type is needed to fully understand the significance of this difference.

The mitral valve showed innervation in both Heart A and B, but Heart C had significantly less nerve staining. Hearts A and B both had clear staining visible from both the superior and inferior side of the anterior leaflet, in the same location and with the same pattern (Figure $1 \mathrm{~b}$ and $\mathrm{c}$, Figure $4 \mathrm{c}$ and e). Heart C, by contrast, showed no visible nerve staining from the superior view, and attenuated nerve stain from the inferior view (Figure $4 \mathrm{~d}$ and $\mathrm{f}$ ). Similar to previous discussions above, if characteristic of parasympathetic innervation, this fits with the current understanding [8]. Additionally, mitral valve prolapse specifically, often a contributory factor in heart failure, is influenced by the same autonomic dysregulation of the heart tied to heart failure, namely sympathetic hyper-innervation with parasympathetic attenuation $[33,34]$.

With respect to the exterior of the pulmonary trunk, specifically where the pulmonary arteries branch, obvious nerve staining was found rimming where the right pulmonary artery had been cut in Heart C (Figure 3f). This result is logical considering the relative abundance of nerves surrounding the various vessels of the heart [11]. This nerve staining was not seen in Heart B, most likely because the pulmonary trunk was cut more proximally than the point staining was observed in Heart C.

In summary, this study demonstrates Sihler's stain can effectively be applied to heart tissue specifically to reveal myelinated nerve fibers. Greater characterization of these nerve fibers is needed, as they could be afferent or efferent vagal fibers, or afferent sympathetic fibers, all of which are myelinated. Significant differences in innervation patterns exist between healthy and heart failure tissue, with the most noted being in the AV node and the mitral valve.

\section{References}

1. Go AS, Mozaffarian D, Roger VL, Benjamin EJ, Berry JD, et al. (2013) Heart disease and stroke statistics--2013 update: a report from the American Heart Association. Circulation 127: e6-6e245. [Crossref]

2. M JB, C EV, J JB (2011) Cardiac autonomic nervous system in heart failure: imaging technique and clinical implications. Curr Cardiol Rev 7: 35-42. [Crossref]

3. Hunt SA, Abraham WT, Chin MH, Feldman AM, Francis GS, et al. (2009) 2009 Focused update incorporated into the ACC/AHA 2005 Guidelines for the Diagnosis and Management of Heart Failure in Adults A Report of the American College of Cardiology Foundation/American Heart Association Task Force on Practice Guidelines Developed in Collaboration With the International Society for Heart and Lung Transplantation. J Am Coll Cardiol 53: e1-e90. [Crossref] 
4. Heidenreich PA, Trogdon JG, Khavjou OA, Butler J, Dracup K, et al. (2011) Forecasting the future of cardiovascular disease in the United States: a policy statement from the American Heart Association. Circulation 123: 933-944. [Crossref]

5. Zipes DP, Wellens HJ (2000) What have we learned about cardiac arrhythmias? Circulation 102: IV52-57. [Crossref]

6. Engstrom G, Hedblad B, Juul-Moller S, Tyden P, Janzon L (2000) Cardiac arrhythmias and stroke: increased risk in men with high frequency of atrial ectopic beats. Stroke 31: 2925-2929. [Crossref]

7. Eisenhofer G, Friberg P, Rundqvist B, Quyyumi AA, Lambert G, et al. (1996) Cardiac sympathetic nerve function in congestive heart failure. Circulation 93: 1667-1676. [Crossref]

8. Florea VG, Cohn JN (2014) The autonomic nervous system and heart failure. Circ Res 114: 1815-1826. [Crossref]

9. Cao JM, Fishbein MC, Han JB, Lai WW, Lai AC, et al. (2000) Relationship between regional cardiac hyperinnervation and ventricular arrhythmia. Circulation 101: 19601969. [Crossref]

10. Li CY, Li YG (2015) Cardiac Sympathetic Nerve Sprouting and Susceptibility to Ventricular Arrhythmias after Myocardial Infarction. Cardiol Res Pract 2015: 698368. [Crossref]

11. Olshansky B, Sabbah HN, Hauptman PJ, Colucci WS (2008) Parasympathetic nervous system and heart failure: pathophysiology and potential implications for therapy. Circulation 118: 863-871. [Crossref]

12. Hasan W (2013) Autonomic cardiac innervation: development and adult plasticity. Organogenesis 9: 176-193. [Crossref]

13. MITCHELL GA (1953) The innervation of the heart. Br Heart J 15: 159-171. [Crossref]

14. Shepherd JT (1985) The heart as a sensory organ. J Am Coll Cardiol 5: 83B-87B. [Crossref]

15. Ulphani JS, Cain JH, Inderyas F, Gordon D, Gikas PV, et al. (2010) Quantitative analysis of parasympathetic innervation of the porcine heart. Heart Rhythm 7: 11131119. [Crossref]

16. Liem RS, Douwe van Willigen J (1988) In toto staining and preservation of peripheral nervous tissue. Stain Technol 63: 113-120. [Crossref]

17. Mu L, Sanders I (2010) Sihler's whole mount nerve staining technique: a review. Biotech Histochem 85: 19-42. [Crossref]

18. Won SY, Kim DH, Yang HM, Park JT, Kwak HH, et al. (2011) Clinical and anatomical approach using Sihler's staining technique (whole mount nerve stain). Anat Cell Biol 44: 1-7. [Crossref]
19. Sihler C (1895) Ueber muskelspindeln und intramuskuläre nervenendigungen bei schlangen und röschen. Arch Mikrosk Anat 46: 709-723.

20. Wharton LR (1937) A technique for studying the innervation of organs. The Anatomical Record 67: 469-475

21. Williams TW (1943) A technique for the gross differential staining of peripheral nerves in cleared vertebrate tissue. The Anatomical Record 86: 189-195.

22. Freihofer WC (1966) The Sihler technique of staining nerves for systematic study especially of fishes. Copeia 3:470-475.

23. Wu BL, Sanders I (1992) A technique for demonstrating the nerve supply of whole larynges. Arch Otolaryngol Head Neck Surg 118: 822-827. [Crossref]

24. Sanders I, Wu BL, Mu L, Biller HF (1994) The innervation of the human posterior cricoarytenoid muscle: evidence for at least two neuromuscular compartments. Laryngoscope 104: 880-884. [Crossref]

25. Sanders I, Wu BL, Mu L, Li Y, Biller HF (1993) The innervation of the human larynx. Arch Otolaryngol Head Neck Surg 119: 934-939. [Crossref]

26. Villani TS, Koroch AR, Simon JE (2013) An improved clearing and mounting solution to replace chloral hydrate in microscopic applications. Appl Plant Sci 1. [Crossref]

27. Marron K, Yacoub MH, Polak JM, Sheppard MN, Fagan D, et al. (1996) Innervation of human atrioventricular and arterial valves. Circulation 94: 368-375. [Crossref]

28. Borin C, Vanhercke D, Weyns A (2006) Innervation of the atrioventricular and semilunar heart valves: a review. Acta Cardiol 61: 463-469. [Crossref]

29. Vijaykumar M, Narula J, Reddy KS, Kaplan EL (1994) Incidence of rheumatic fever and prevalence of rheumatic heart disease in India. Int J Cardiol 43: 221-228. [Crossref]

30. Swanson JC, Krishnamurthy G, Itoh A, Kvitting JP, Bothe W, et al. (2012) Vagal nerve stimulation reduces anterior mitral valve leaflet stiffness in the beating ovine heart. $J$ Biomech 45: 2007-2013. [Crossref]

31. Yacoub MH, Cohn LH (2004) Novel approaches to cardiac valve repair: from structure to function: Part I. Circulation 109: 942-950. [Crossref]

32. Kovach JA, Gottdiener JS, Verrier RL (1995) Vagal modulation of epicardial coronary artery size in dogs. A two-dimensional intravascular ultrasound study. Circulation 92: 2291-2298. [Crossref]

33. Hu X, Wang HZ, Liu J, Chen AQ, Ye XF, et al. (2014) A novel role of sympathetic activity in regulating mitral valve prolapse. Circ J 78: 1486-1493. [Crossref]

34. Hu X1, Zhao Q (2011) Autonomic dysregulation as a novel underlying cause of mitral valve prolapse: a hypothesis. Med Sci Monit 17: HY27-31. [Crossref]

Copyright: (C2018 Hilton A. This is an open-access article distributed under the terms of the Creative Commons Attribution License, which permits unrestricted use, distribution, and reproduction in any medium, provided the original author and source are credited. 